\title{
Population status, structure and distribution of the greater one-horned rhinoceros Rhinoceros unicornis in Nepal
}

\author{
Naresh Subedi, Shant Raj Jnawali, Maheshinar Dhakal \\ Narendra M.B. Pradhan, Babu Ram Lamichiane, Sabita Malla \\ RAJAN AMIN and YADVENDRADEV V. JHALA
}

\begin{abstract}
We assessed the abundance and distribution of the greater one-horned or Indian rhinoceros Rhinoceros unicornis in all its potential habitats in Nepal, using block counts. In April $20115,497 \mathrm{~km}$ were searched in 3,548 elephant-hours over 23 days. The validity of the block count was assessed by comparing it with counts obtained from long-term monitoring using photographic identification of individual rhinoceroses (ID-based), and estimates obtained by closed population sighting-mark-resighting in the $214 \mathrm{~km}^{2}$ of Chitwan National Park. A total of 534 rhinoceroses were found during the census, with 503 in Chitwan National Park (density $1 \mathrm{~km}^{-2}$ ), 24 in Bardia National Park $\left(0.28 \mathrm{~km}^{-2}\right)$ and seven in Suklaphanta Wildlife Reserve $\left(0.1 \mathrm{~km}^{-2}\right)$. In Chitwan $66 \%$ were adults, $12 \%$ subadults and $22 \%$ calves, with a female : male ratio of 1.24 . The population estimate from sighting-mark-resighting was 72 (95\% CI 71-78). The model with different detection probabilities for males and females had better support than the null model. In the Sauraha area of Chitwan estimates of the population obtained by block count (77) and ID-based monitoring (72) were within the $95 \%$ confidence interval of the estimate from sighting-mark-resighting. We recommend a country-wide block count for rhinoceroses every 3 years and annual IDbased monitoring in a sighting-mark-resighting framework within selected subpopulations. The sighting-mark-resighting technique provides the statistical rigour required for population estimates of the rhinoceros in Nepal and elsewhere.
\end{abstract}

Keywords Block count, Chitwan National Park, greater one-horned rhinoceros, ID-based monitoring, Nepal,

Naresh Subedi*, Shant Raj Jnawali and Babu Ram LamichHane National Trust for Nature Conservation, Khumaltar, Kathmandu

MAHESHWAR DHAKal Department of National Parks and Wildlife Conservation, Babarmahal, Kathmandu

Narendra M.B. Pradhan and Sabita Malla WWF Nepal, Baluwatar, Kathmandu

RajAN AMIN Zoological Society of London, Regents Park, London, UK

YADVENDRADEV V. JHALA (Corresponding author) Wildlife Institute of India, P.O. Box 18, Dehradun 248001, India. E-mail jhalay@wii.gov.in

*Also at: Wildlife Institute of India, Dehradun, India

Received 9 November 2012. Revision requested 7 January 2013.

Accepted 20 March 2013. population estimation, Rhinoceros unicornis, sightingmark-resighting

This paper contains supplementary material that can be found online at http://journals.cambridge.org

\section{Introduction}

T egaherbivores are globally threatened as a result of 1 habitat conversion, fragmentation and poaching to fulfil the illegal demand for their body parts. Populations of such species are mostly confined in small, isolated protected areas (Owen-Smith, 1988; Sukumar, 1989). The populations of the Indian or greater one-horned rhinoceros Rhinoceros unicornis in Asia have thus been seriously compromised. In the 15th century rhinoceroses were abundant throughout the floodplains of the Ganges, Brahmaputra and Sindh Rivers and their large tributaries between the Indo-Burmese border in the east and Pakistan in the west (Blanford, 1891; Laurie, 1978; Dinerstein, 2003). At present c. 2,800 rhinoceroses survive, in protected areas in India and Nepal (Talukdar, 2009).

Rhinoceroses suffered a catastrophic decline in Nepal during the 1960s, when the population was reduced to $<100$ individuals and confined to the Chitwan valley. The decline was attributed to loss of habitat and poaching that resulted from conversion of terai grasslands and forests to agriculture following malaria eradication and settlement programmes (Laurie, 1978). During the 1960 s $>70 \%$ of the forests were cleared in Chitwan valley alone (Caughley, 1969; Laurie, 1978; Dinerstein, 2003). After the establishment of Chitwan National Park in 1973 and strict law enforcement the rhinoceros population gradually recovered to c. 612 in 2000 (DNPWC, 2000; Dinerstein, 2003). During this period intensive protection and metapopulation management resulted in the establishment of populations in Bardia Karnali floodplain (c. 32 individuals), Bardia Babai valley (c. 35), and Suklaphnata Wildlife Reserve (c. 5). Subsequently, during the armed conflict of 1996-2005, rhinoceros conservation in Nepal was compromised by poaching, resulting in local extinction of the Babai population, reduction of the Bardia Karnali population to 22, the Suklaphanta population to four and the Chitwan 


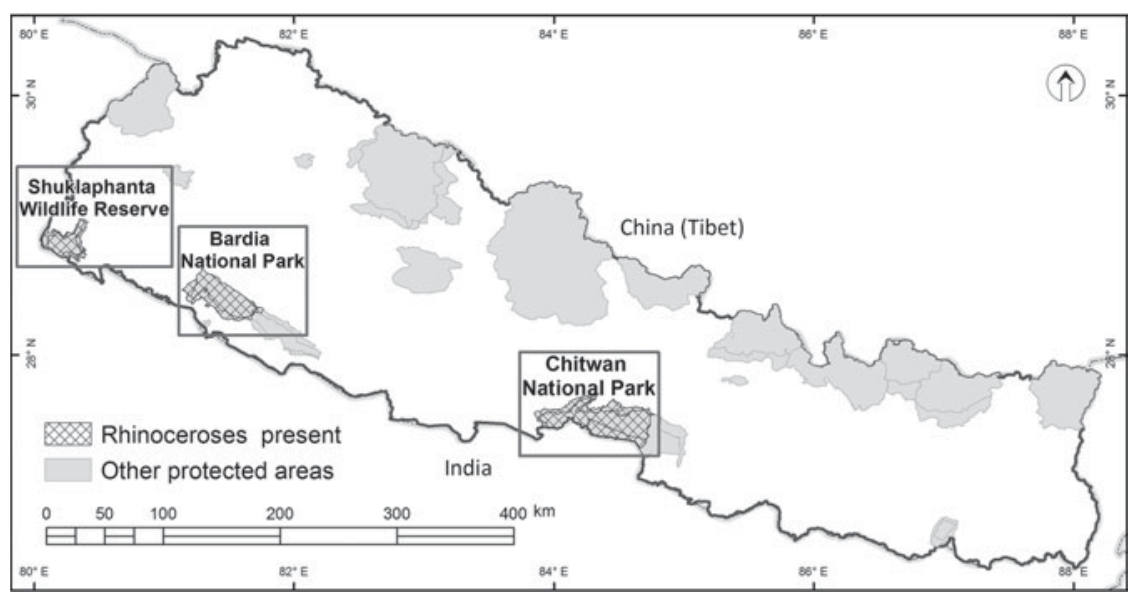

FIG. 1 Protected areas that were surveyed for estimating the population of the greater one-horned rhinoceros Rhinoceros unicornis in Nepal. These three sites are the only known areas where rhinoceroses occur in the country. population to 372 (Thapa et al., 2013). The total population in Nepal was c. 400 in 2005 (DNPWC, 2005).

Because of its late age at first calving, long gestation period, long inter-calving interval and single offspring the rhinoceros is a highly $\mathrm{K}$-selected species and hence vulnerable to extinction by deterministic factors such as poaching (Poudyal et al., 2009). Regular monitoring of populations is therefore essential to guide protection efforts and management decisions.

White Ceratotherium simum and black Diceros bicornis rhinoceroses in Africa have been monitored and their populations estimated using individual identification based on distinct identifying features (Conway \& Goodman, 1989; Kiwia, 1989; Walpole et al., 2001; Patton et al., 2007), radio tagging (Galli \& Flamand, 1996), spoor (Alibhai et al., 2008) and camera traps (Stein et al., 2010). Aerial counts from fixed winged aircraft and helicopters using multiple observers (Brockett, 2002; Ngene et al., 2011), and counts at water holes from photographs (Cilliers, 1989) have also been used to monitor and estimate population sizes. The accuracy and precision of various methods were tested with a known population of black rhinoceroses in Etosha National Park (Cilliers, 1989) and Kruger National Park (Ferreira et al., 2011). Aerial surveys were found to consistently underestimate the population (Laurie, 1978; Brockett, 2002; Ngene et al., 2011). Laurie (1978) and Dinerstein \& Price (1991) used photography to develop a catalogue of individual rhinoceroses, to estimate the minimal population size in Chitwan. Since 2000 the population of rhinoceroses in Nepal has been enumerated every $4-5$ years by the total block count method, by observers riding tame elephants Elephas maximus. These total counts are similar to the aerial block counts in Africa (Brockett, 2002). The tall grass and closed canopy forests of the terai make aerial surveys impractical. Elephants are readily available in Nepal and are regularly used for patrolling, and can negotiate the habitat and provide vantage points for detecting and counting rhinoceroses (Laurie, 1978; Dinerstein \& Price, 1991). Since 2008 in Bardia National Park, Suklaphanta Wildlife Reserve and parts of Chitwan National Park all individuals have been identified and monitored by regular patrols in a system similar to that used for eastern black rhinoceroses in Kenya (Amin et al., 2006).

Here, we report the status of the rhinoceros in Nepal in 2011 using the total block count method across all rhinoceros habitats. This method does not explicitly account for imperfect detections but this may be a minor problem for surveys of a large-bodied animal such as the rhinoceros. However, we test this assumption within an intensive study area where we compare the population estimate obtained by block counts with estimates obtained from intensive longterm monitoring based on individual identity (ID-based) and from closed population sighting-mark-resighting; the latter explicitly accounts for imperfect detections.

\section{Study area}

The greater one-horned rhinoceros is a habitat specialist, primarily restricted to tall grasslands of floodplains and riverine forest, and rarely found in hills and sal Shorea robusta forests (Laurie, 1978; Dinerstein, 2003). The study covered the current distribution of the rhinoceros within all potential rhinoceros habitats in Chitwan National Park, Bardia National Park (including the narrow c. $13 \mathrm{~km}$ Khata forest corridor along the Geruwa River that connects Bardia with Katarniaghat Wildlife Sanctuary in India), and Suklaphanta Wildlife Reserve (Fig. 1).

The $932 \mathrm{~km}^{2}$ Chitwan National Park (henceforth Chitwan) lies in south central Nepal. The climate is subtropical monsoonal with three distinct seasons: monsoon (June-October), cool-dry (October-February) and hot-dry (February-June). Mean annual temperature range between 1980 and 2009 was a minimum $8{ }^{\circ} \mathrm{C}$ in January and a maximum $36^{\circ} \mathrm{C}$ in April. Chitwan receives 2,036 \pm SE $64 \mathrm{~mm}$ of rainfall per year, $>80 \%$ of which falls in the monsoon (Subedi, 2012). The Park harbours 68 species of mammals, 544 species of birds, 56 species of reptiles and amphibians, and 126 species of fish (CNP, 2012). In addition to the 


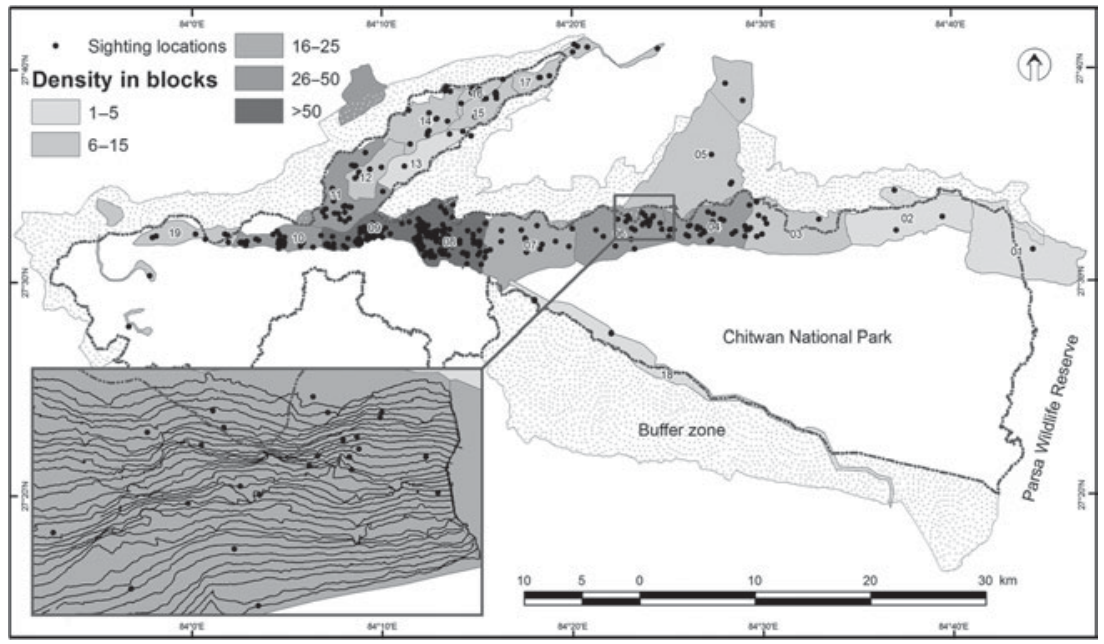

FIG. 2 Rhinoceros distribution and density $\left(\mathrm{km}^{-2}\right)$ gradient in Chitwan National Park (Fig. 1) in 2011, as determined by block counts (blocks are numbered; see text for further details). The inset shows the tracks of the survey lines within part of Block 6 . greater one-horned rhinoceros, the large mammals include tiger Panthera tigris, gaur Bos gaurus, Asian elephant Elephas maximus, leopard Panthera pardus, sloth bear Melursus ursinus, sambar Rusa unicolor and chital Axis axis.

The $968 \mathrm{~km}^{2}$ Bardia National Park (henceforth Bardia) is the largest park in south-western lowland Nepal. The flora, fauna and climate is similar to Chitwan but Bardia receives less rainfall. Eighty three rhinoceroses were reintroduced in Bardia ( 13 in the Karnali floodplain and 70 in Babai valley) from Chitwan between 1986 and 2003, to create a second rhinoceros population in Nepal (Dinerstein, 2003; DNPWC, 2009). Details of the reintroduced rhinoceroses are provided by Jnawali \& Wegge (1993), Jnawali (1995) and Dinerstein (2003).

The $305 \mathrm{~km}^{2}$ Suklaphanta Wildlife Reserve (henceforth Suklaphanta) lies in the far west of the lowland terai and is drier than Chitwan and Bardia, with 1,300-2,300 $\mathrm{mm}$ of rainfall annually. It has 24 species of mammals, 350 species of birds and 14 species of fishes (DNPWC, 2009). The rhinoceros population was supplemented in 2003 with the translocation of four animals from Chitwan to add to one resident rhinoceros that was first sighted and reported in 1995, possibly a migrant from the reintroduced population in Dudhwa National Park, India (DNPWC, 2009).

\section{Methods}

\section{Block count method}

We conducted the rhinoceros census during 5-23 April 2011, when visibility was most suitable following the annual burning of the tall grasslands and leaf shedding by deciduous trees (Dinerstein \& Price, 1991). The survey covered all potential rhinoceros habitats in Chitwan $\left(503 \mathrm{~km}^{2}\right)$ including Barandabhar forest corridor and community managed forests. In Bardia $86 \mathrm{~km}^{2}$ were covered, including the Karnali floodplain, community-managed forests, and the Khata forest corridor, which is contiguous with Katerniaghat Wildlife Sanctuary in India. Suklaphanta was not censused as the population of seven rhinoceroses was individually known through a regular ID-based monitoring programme.

We used a block count method in which parallel strip transects were surveyed simultaneously from elephants (DNPWC, 2009). Using a 1:25,000 topographic map and reconnaissance surveys we divided all potential rhinoceros habitats into blocks of $11-75 \mathrm{~km}^{2}$ based on physical features that probably curtail short-term movements of rhinoceroses and thus minimize movements between blocks on subsequent days (Figs 2 \& 3). A block bounded by streams, ridges and sal forest (Laurie, 1978; Dinerstein \& Price, 1991) was considered a sampling unit and was surveyed in a single day.

We used 40 elephants in Chitwan and 15 elephants in Bardia, to survey each block systematically. The total census comprised 19 days in Chitwan and 5 days in Bardia, with a search effort of 3,548 elephant-hours. A total of $5,497 \mathrm{~km}$ were surveyed, comprising 4,854 km in Chitwan and $643 \mathrm{~km}$ in Bardia. Each elephant had a trained observer and a mahout on the back. Elephants were lined up and moved parallel along transects, at a spacing of $50 \mathrm{~m}$ in dense forests and $100-200 \mathrm{~m}$ in open grasslands, to account for differential detectability in these habitats. Elephants were walked at a mean speed of 1-2 km per hour. Each elephant team was equipped with a camera, datasheets, global positioning system (GPS) loaded with the day's track, and a wireless radio handset, for navigation and coordination.

To prevent double counting rhinoceroses were recorded only after they had passed the line of elephants. All rhinoceros sightings were communicated by radio to confirm with observers on adjacent transects, and location, time of sighting, habitat type, group size, direction of movement, age and sex, with any distinguishing features, and 


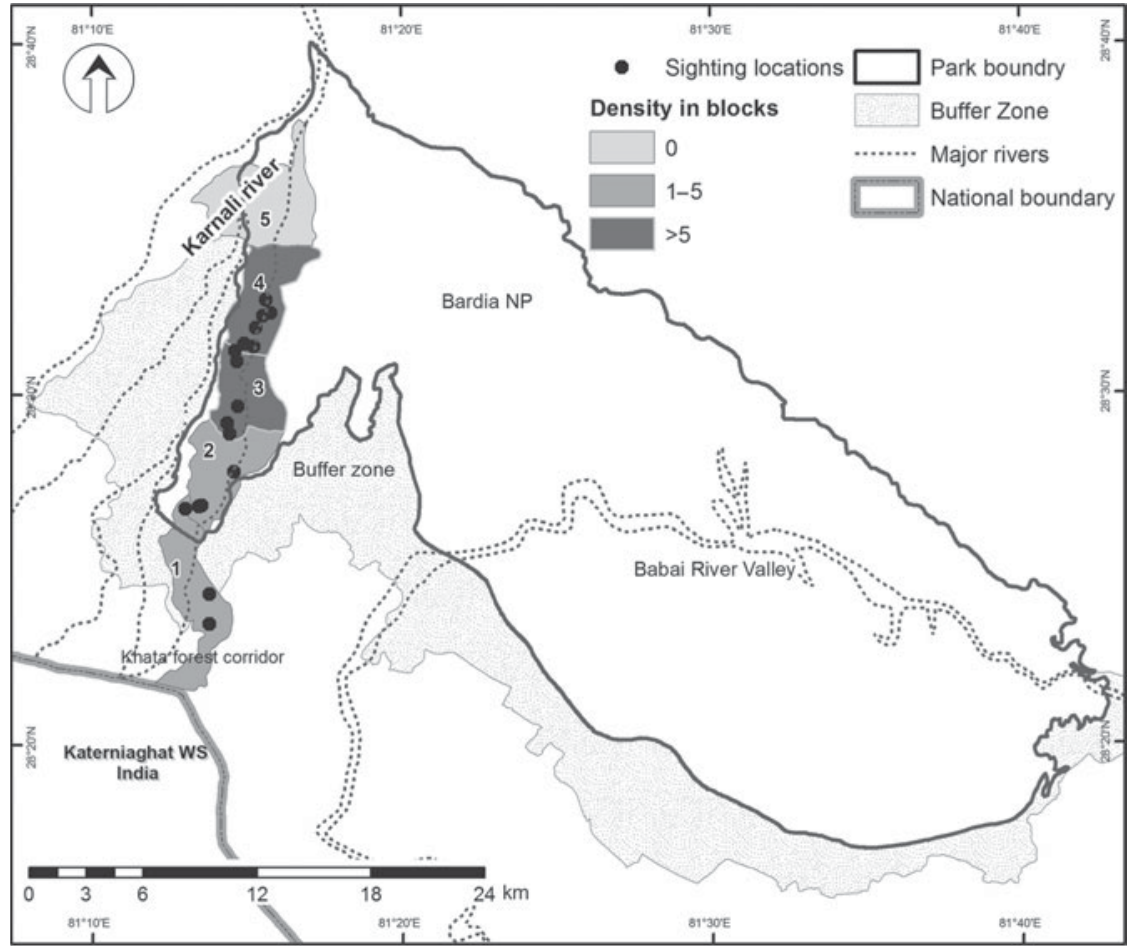

FIG. 3 Rhinoceros distribution and density $\left(\mathrm{km}^{-2}\right)$ in Bardia National Park (Fig. 1) in 2011, as determined by block counts (blocks are numbered; see text for further details). photographs, were recorded for each individual. Age was categorized as calf, subadult and adult (Laurie, 1978). Fiftyfive observers participated, all previously trained in survey techniques for rhinoceroses and tested for consistency in ageing and sexing. If age and sex could not be confirmed individuals were recorded as unsexed and unaged. Observers, mahouts and coordinators were debriefed each evening and any potential double counts corrected and data compiled for the surveyed block, to obtain a total count. Encounter rates of rhinoceroses were computed by dividing the total number recorded by the search effort in $\mathrm{km}$. Density was obtained by dividing the total number of rhinoceroses in a block by the block area, computed with ArcGIS v. 9.3 (ESRI, Redlands, USA).

\section{Validating block counts}

The block count method assumes a detection probability of one, resulting in a total count. Because of its large size, way of moving when approached and the intensive survey effort, this assumption was probably valid for the rhinoceros. However, we checked this by comparing the population estimate obtained by (1) long-term ID-based monitoring of individual rhinoceroses in the $214 \mathrm{~km}^{2}$ Sauraha area of Chitwan (Block 1-5, Fig. 2), and (2) closed population sighting-mark-resighting population estimation conducted immediately prior to the block count in Sauraha (see below).

Most rhinoceroses can be identified individually from features such as horn shape, skin folds and body marks
(Laurie, 1982; Dinerstein \& Price, 1991). We had been monitoring rhinoceroses by individual identification on a weekly basis in the study areas for the past 3 years. Mahouts and senior wildlife technicians from the National Trust for Nature Conservation routinely search and record individual rhinoceroses whose profile includes full body photographs highlighting distinguishing characteristics, sex, age and information about locations and associated rhinoceroses (Conway \& Goodman, 1989; Walpole et al., 2001; Amin et al., 2006). A few rhinoceroses, mostly subadults, do not have any recognizable features but these comprise only $2-5 \%$ of all sightings; such individuals were distinguished from others by their location and range use, and from associated identified rhinoceroses. This intensive and extensive monitoring allowed us to determine the total population in our study areas with reasonable certainty (Walpole et al., 2001).

Two weeks prior to the total count we estimated the subpopulation in Sauraha using sighting-mark-resighting of individually identified rhinoceroses. We divided the $214 \mathrm{~km}^{2}$ area into a grid of $1 \times 1 \mathrm{~km}$ cells, which were intensively searched from the backs of 13 elephants, each with two observers. The entire area was covered within a period of 4 days, and this was done three times consecutively over 12 days (726 elephant hours). We attempted to ensure demographic and geographical closure by this short sampling interval and the delineation of the area, which is mostly bounded by non-rhinoceros habitat. Population closure was also formally tested using the closure test (Otis et al., 1978; Stanley \& Burnham, 1999). On sighting of a 
TABLE 1 Population status and structure of the greater one-horned rhinoceros Rhinoceros unicornis in three protected areas in Nepal (Fig. 1) in April 2011.

\begin{tabular}{lrrrr}
\hline $\begin{array}{l}\text { Age group } \\
\text { (by protected area) }\end{array}$ & Female & Male & Unidentified & Total \\
\hline Chitwan National Park & & & & \\
Adult & 157 & 126 & 49 & 332 \\
Subadult & 14 & 9 & 37 & 60 \\
Calf & 12 & 10 & 89 & 111 \\
Subtotal & 183 & 145 & 175 & 503 \\
Bardia National Park & & & & \\
Adult & 7 & 4 & 4 & 15 \\
Subadult & 1 & 0 & 3 & 4 \\
Subtotal & 9 & 5 & 10 & 24 \\
Suklaphanta Wildlife & & & & \\
$\quad$ Reserve & & & & 4 \\
Adult & 2 & 2 & 0 & 2 \\
Subadult & 0 & 0 & 2 & 7 \\
Subtotal & 2 & 2 & 3 & 534 \\
Total & 194 & 152 & 188 & \\
\hline
\end{tabular}

rhinoceros the observers either identified it based on a catalogue of photographs that they carried and/or they took photographs, which were later used to identify the individual. The data over the three 4-day occasions were then organized in an X capture matrix and analysed with MARK (White \& Burnham, 1999) using Huggins closed capture models (Amstrup et al., 2005). As ranging patterns of male and female rhinoceroses are known to differ (Dinerstein, 2003; Subedi, 2012) we expected a priori that detections would differ between genders. Because there was a similar effort on all three occasions we did not expect temporal variation in capture probabilities or a trap response to our sampling. We therefore used Akaike information criteria (AIC) based model selection in MARK to select between the null model (constant capture probabilities) and a model with heterogeneity as a result of gender. The population sizes obtained by total block counts and from ID-based monitoring were then compared with the 95\% confidence interval of the estimate obtained by sightingmark-resighting.

\section{Results}

\section{Abundance and distribution}

The 2011 survey recorded a total of 503 rhinoceroses in Chitwan, 24 rhinoceroses in Bardia, and seven rhinoceroses in Suklaphanta, giving a total rhinoceros population of 534 animals for Nepal (Table 1). In Chitwan 48 animals (9.54\%) were recorded outside the park in community forests and Barandabhar forest corridor (Fig. 2). The highest concentration of rhinoceroses was in Blocks 8 and 9 (Sukhibar to
Temple tiger; Table 2). This area of $48 \mathrm{~km}^{2}$ holds $46.5 \%$ of the rhinoceroses in Chitwan. The density and encounter rate were lowest in Blocks 1 and 2, in the east.

All of the rhinoceroses in Bardia were confined to the Karnali floodplain, of which two were outside the Park, within Khata forest corridor (Fig. 3). No rhinoceroses or their signs were found in the Babai valley. The seven rhinoceroses in Suklaphanta were found along the Chaudhar and Mahakali river floodplains.

\section{Comparison of methods for population estimation}

The total rhinoceros population estimated by the block count method in the Sauraha area of Chitwan was 77 (Blocks 1-5, Table 2). Long-term ID-based monitoring in this area has resulted in a database of 67 individually identified rhinoceroses and photographs of five subadults that do not have clear identifying features. We considered these subadults to be unique individuals based on their temporal and spatial separation and simultaneous sighting of 2-3 individuals in one group. There were also three individually identifiable adult rhinoceroses that occasionally used the area. These $72-75$ individuals were known to occupy Sauraha at any one time.

During sighting-mark-resighting in Sauraha we obtained 168 sightings of 66 unique individuals and five unidentified individuals. Closure tests indicated that the assumptions of a closed population was not violated (closure test: $\chi^{2}=0.85, \mathrm{P}=0.35$, Stanley \& Burnham, 1999; $z=2.88$, $\mathrm{P}=0.99$, Otis et al., 1978). The model incorporating a gender-based group effect was selected by MARK over the null model, with a $\triangle \mathrm{AIC}=2.9$ and a capture probability for female rhinoceroses of $\hat{p}=0.74 \pm$ SE 0.05 and for males of $\hat{p}=0.88 \pm$ SE 0.04. With an estimated 37 (95\% CI 36-41) females and 30 (95\% CI 30-32) males, the population in Sauraha was estimated to be 67 (95\% CI 66-73). As the number of unidentified rhinoceroses in the area was known to be five the $95 \%$ CI was adjusted to be $71-78$. The total number of rhinoceroses from both the block counting and the ID-based monitoring were within the $95 \%$ confidence intervals of the sighting-mark-resighting estimate.

\section{Population structure}

Of the 503 rhinoceroses recorded in Chitwan 66\% were adults, $12 \%$ subadults and $22 \%$ calves (Table 1 ). Thirty five percent of the adult animals could not be sexed. Of those that were sexed the adult female:male ratio was 1.24 in Chitwan $(n=283)$ and $1.75(n=17)$ in Bardia. Sixty and $55 \%$ of the adult females had calves in Chitwan and Bardia, respectively. Of the 24 rhinoceroses in the Bardia population $62 \%$ were adults, $21 \%$ subadults and $17 \%$ calves. 
TABLE 2 Block size, number of rhinoceroses, density and encounter rate in the 19 census blocks in Chitwan National Park (Fig. 1) in April 2011.

\begin{tabular}{|c|c|c|c|c|c|c|}
\hline $\begin{array}{l}\text { Block } \\
\text { number* }^{*}\end{array}$ & Block name & $\begin{array}{l}\text { No. of } \\
\text { rhinoceroses }\end{array}$ & $\begin{array}{l}\text { Block size } \\
\left(\mathrm{km}^{2}\right)\end{array}$ & $\begin{array}{l}\text { Search effort } \\
(\mathrm{km})\end{array}$ & $\begin{array}{l}\text { Density } \\
\left(\mathrm{km}^{-2}\right)\end{array}$ & $\begin{array}{l}\text { Encounter } \\
\text { rate } \mathrm{km}^{-1} \\
\end{array}$ \\
\hline$\overline{1}$ & Sunachuri, Harda & 1 & 46.3 & 318.0 & 0.02 & $<0.01$ \\
\hline 2 & Harda, Amrite, Kuchkuche & 4 & 34.9 & 310.8 & 0.11 & 0.01 \\
\hline 3 & Amrite, Marchauli, Icharny & 19 & 33.5 & 392.4 & 0.57 & 0.05 \\
\hline 4 & Barandabhar corridor & 7 & 24.9 & 517.5 & 0.28 & 0.01 \\
\hline 5 & Marchauli, Dumaria & 46 & 74.7 & 235.2 & 0.62 & 0.20 \\
\hline 6 & Dumaria, Kasara & 34 & 31.6 & 265.6 & 1.07 & 0.13 \\
\hline 7 & Kasara, Kamaltal & 17 & 38.7 & 273.0 & 0.44 & 0.06 \\
\hline 8 & Sukibhar, Rapti-Reu junction & 164 & 29.3 & 510.7 & 5.60 & 0.32 \\
\hline 9 & Reu-Khoraimuhan, & 70 & 17.9 & 197.7 & 3.90 & 0.35 \\
\hline 10 & Khoria, Temple tiger & 43 & 12.0 & 195.0 & 3.58 & 0.22 \\
\hline 11 & Gharial island, Lamichur, Kawasoti & 26 & 38.5 & 238.1 & 0.67 & 0.11 \\
\hline 12 & Gharial island, Bhorsaghat & 10 & 11.7 & 183.5 & 0.86 & 0.05 \\
\hline 13 & Bhagedi, Seri, Tamsapur & 3 & 15.1 & 246.2 & 0.20 & 0.01 \\
\hline 14 & Main island of Bandarjhula & 13 & 20.0 & 222.2 & 0.65 & 0.06 \\
\hline 15 & Bhorsaghat, Kujauli & 12 & 10.5 & 132.7 & 1.12 & 0.09 \\
\hline 16 & Mardighol, Gajapur & 8 & 4.9 & 126.1 & 1.63 & 0.06 \\
\hline 17 & Kujauli, Sikrauli & 11 & 11.6 & 258.0 & 0.95 & 0.04 \\
\hline 18 & Madi, Thori & 4 & 27.7 & 119.5 & 0.14 & 0.03 \\
\hline 19 & Seri, Tribeni & 11 & 19.2 & 75.0 & 0.57 & 0.15 \\
\hline Total & & 503 & 503 & 4,817 & & \\
\hline
\end{tabular}

${ }^{\star}$ See Fig. 2 for location of blocks.

\section{Discussion}

The female: male ratio of the greater one-horned rhinoceroses in Chitwan was 1.58 in 1988 (Dinerstein \& Price, 1991) compared to 1.24 in our study in 2011. In 1975 there were $52.2 \%$ adults, $21.2 \%$ subadults and $26.6 \%$ calves (Laurie, 1982), and the population structure was similar in 1988 and 1994 (Dinerstein \& Price, 1991; Yonzon, 1994). The maximum proportion of adults was recorded (68.75\%) in 2005 , and it was $66 \%$ in our study. The high percentage of adults in the rhinoceros population in Chitwan during 2005 was probably because of the poaching of breeding females in 2002 and 2003. The increase in the percentage of males in Chitwan may also be attributed to male-biased births in rhinoceroses (Lang et al., 1977) and removal of females for reintroductions and captive breeding. A total of 103 individuals were removed from Chitwan for conservation breeding and reintroduction after 1984 , of which $>70 \%$ were females (NTNC, unpubl. data). However, the population structure in 1975 and 2011 was not significantly different $\left(\chi^{2}=16.3\right.$, $\mathrm{df}=12, \mathrm{P}=0.18$ ).

Of the 503 rhinoceroses recorded in Chitwan 9.5\% were located outside the Park, in Barandabhar forest corridor and community forests in the buffer zone. Dispersal of rhinoceroses outside the Park is a challenge for security but is also an opportunity for partnership with local communities in rhinoceros conservation. The community forests can be used for nature-based tourism (Bookbinder et al., 1998).
Because of strong community engagement in rhinoceros conservation in the buffer zone and the corridor, poaching has been sharply reduced in these areas. However, the security of these rhinoceroses and human-rhinoceros conflict is a constant challenge for Park management.

The temporal and spatial distribution of rhinoceroses has changed in Chitwan. There has been a continuous decline of the Sauraha subpopulation. From 252 rhinoceroses in 1988 (Dinerstein \& Price, 1991) the population declined by $49 \%$ to 128 in 2011. However, the rhinoceros population in Chitwan west of Kasara is gradually increasing. Reasons for the decline in Sauraha could be: (1) The removal of 65 rhinoceroses during 1984-2003 for reintroduction and captive breeding (DNPWC, 2009; NTNC, unpubl. data). (2) Of the 171 rhinoceroses poached during 1998-2010, $48 \%$ were from this small area; about $60 \%$ of the poachers arrested in the Chitwan valley were from villages c. $20 \mathrm{~km}$ north of Sauraha (NTNC, unpubl. data) and therefore we suspect there was an even higher pressure from poaching in this area than recoded, especially during the period of armed conflict. (3) Annual monsoon floods are responsible for maintaining prime grazing habitat and high population densities in Chitwan (Laurie, 1978; Dinerstein \& Price, 1991), and rivers flowing through the terai are laden with silt from the mountains, and often change course, forming alluvial grasslands and oxbow lakes that are prime rhinoceros habitat; the establishment of a $9 \mathrm{~km}$ long dyke along the northern bank of the Rapti River between Kumrose and 
Lothar during the 1990s channelled river flow in place of a meandering, silt depositing flow, thereby possibly lowering the carrying capacity of this area for rhinoceroses.

The decline of the Sauraha subpopulation could be reversed by translocation of individuals from the western subpopulation in Chitwan but only after a study of the causes of decline, to ensure that these factors are controlled by habitat management and antipoaching activities. The small population in Suklaphanta necessitates supplementation of individuals. For Bardia, studies on habitat availability, demography and security threats are needed to guide further supplementation of rhinoceroses. In the Babai valley of Bardia 70 rhinoceroses were released during 1991-2003 and all were poached during armed conflict (DNPWC, 2009). Some of the rhinoceroses from Bardia have dispersed to India, to Katerniaghat Wildlife Sanctuary (Jnawali, 1995; DNPWC, 2009), through the Khata forest corridor, which still serves as a corridor for movement of rhinoceroses, elephants and tigers between Nepal and India, connecting the transboundary Terai Arc Landscape (Jhala et al., 2011). Some 4-6 individuals were reported in Katerniaghat Wildlife Sanctuary in April 2011 (R. Thapa, pers. comm.).

During 2011-2012 poaching of rhinoceroses has been substantially reduced, from a mean of 12 per year to c. 2 per year (Subedi, 2012). The current integrated antipoaching strategy (intensive strategic patrolling, monitoring in core areas, an effective intelligence network and arrests by the Wildlife Crime Control Bureau through coordination among all security agencies), seems to be effective. More than 150 poachers were arrested, and imprisoned, across Nepal during 2010-2011 (DNPWC, 2011). However, poaching can escalate at any time, especially during periods of political instability. In addition, habitat degradation by Mikania micrantha, which has invaded $>15 \%$ of prime rhinoceros habitat, and the succession of tall grasslands to woodlands, have the potential to reduce carrying capacity for the rhinoceros and to retard population growth (Murphy et al., 2013; Subedi, 2012). However, $60 \%$ of females of breeding age have calves in Chitwan; this is a good indicator of a healthy population, especially for highly Kselected species such as the rhinoceros.

The Sauraha area is large $\left(214 \mathrm{~km}^{2}\right)$ and is a separate subpopulation of rhinoceroses within Chitwan National Park as it is bounded by non-rhinoceros habitat to the east, north, and south but remains connected with the other Chitwan rhinoceros subpopulation, to the west. Telemetry data for eight rhinoceroses (Subedi, 2012) and long term ID-based monitoring suggests that movement between the Sauraha subpopulation and rhinoceroses elsewhere in Chitwan is rare. We therefore believe that the population in Sauraha was geographically closed during our 12-day sighting-mark-resighting survey, as also suggested by the closure test. A priori we expected heterogeneity in capture probability between males and females, and selection in $M A R K$ of the model with gender effect over the null model supports this hypothesis. As our marking technique was based on photography and sighting of individually known rhinoceroses we did not expect capture and recapture probabilities to differ, and as we used the same elephants, mahouts and observers and invested similar effort to locate rhinoceroses on all three occasions we did not expect capture probabilities to vary over time. The population estimates obtained by sighting-mark-resighting were reasonably precise, with a coefficient of variation of $4.5 \%$.

By designing appropriate surveys in a mark-recapture framework, robust population estimates are possible for this species of rhinoceros. The tall grasslands and dense riverine forests of the terai makes aerial and transect counts, as used for rhinoceroses in Africa, inaccurate in Nepal (Laurie, 1978). Our comparison of the total block and intensive ID-based counts with the statistically robust sightingmark-resighting method suggests that these methods are comparable. When the population is $>300$ ID-based monitoring requires a relatively long time $\left(>_{1}\right.$ year) for the preparation of profiles of individual rhinoceroses but the method can be effective for populations of $<100$ within c. 2 months. The total block count method is relatively quick but demands greater resources and precautions and planning to avoid double or under-counts. Sighting-markresighting is dependent on having a catalogue of individually identified rhinoceroses and therefore ID-based monitoring is a prerequisite. As most protected area guard posts have captive elephants for patrolling and wildlife monitoring in Nepal, ID-based monitoring of rhinoceroses is feasible. This form of monitoring can deter poaching (Thapa et al., 2013), and has the potential to provide robust population estimates as well as life history information if executed systematically (Amin et al., 2006).

We propose that the countrywide status of the greater one-horned rhinoceros is monitored by a combination of all three methods, with a countrywide block count for rhinoceroses every 3 years and annual ID-based monitoring in a sighting-mark-resighting framework within selected subpopulations. Sighting-mark-resighting provides statistical rigour for estimating rhinoceros populations, and can be readily adapted to estimate other rhinoceros populations in Asia and Africa for which ID-based profiles are available.

\section{Acknowledgements}

We thank the Department of National Parks and Wildlife Conservation and former Director General Mr Krishna Prasad Acharya for support and cooperation. WWF Nepal, the Zoological Society of London, National Trust for Nature Conservation (NTNC) and US Fish and Wildlife Service provided funds for the census and rhinoceros monitoring 
programme. We acknowledge the contribution to rhinoceros conservation by the staff of Chitwan and Bardia National Parks, Suklaphanta Wildlife Reserve, NTNC and WWF Nepal. We acknowledge the Wildlife Institute of India for providing support during the preparation of this manuscript.

\section{References}

Alibhai, S.K., Jewell, Z.C. \& Law, P.R. (2008) A footprint technique to identify white rhino Ceratotherium simum at individual and species level. Endangered Species Research, 4, 205-218.

Amin, R., Okita-Ouma, B., Aadcock, K., Emslie, R.H., Mulama, M. \& Pearce-Kelly, P. (2006) An integrated management strategy for the conservation of eastern black rhinoceros (Diceros bicornis michaeli) in Kenya. International Zoo Yearbook, 40, 118-129.

Amstrup, S.C., McDonald, T.L. \& Manly, B.F.J. (eds) (2005) Handbook of Capture-Recapture Analysis. Princeton University Press, Princeton, USA.

Blanford, W.T. (1891) The Fauna of British India, including Ceylon and Burma. Taylor and Francis, London, UK.

Bookbinder, M.P., Dinerstein, E., Rijal, A., Cauley, H. \& Rajouria, A. (1998) Ecotourism's support of biodiversity conservation. Conservation Biology, 12, 1399-1404.

Brockett, B.H. (2002) Accuracy, bias and precision of helicopter-based counts of black rhinoceros in Pilanesberg National Park, South Africa. South African Journal of Wildlife Research, 2, 121-135.

Caughley, G. (1969) Wildlife and Recreation in the Trishuli Watershed and other Areas in Nepal. HMG/FAO/UNDP Trishuli Watershed Development project, Project Report No. 6, Kathmandu, Nepal.

Cilliers, A. (1989) Monitoring methods and techniques for censusing black rhinoceros Diceros bicornis in Etosha National Park. KOEDOE, 2, 49-60.

CNP (Chitwan National Park) (2012) Biodiversity: Chitwan National Park, Chitwan. Http://www.chitwannationalpark.gov.np [accessed 25 July 2012].

Conway, J.J. \& Goodman, P.S. (1989) Population characteristics and management of black rhinoceros Diceros bicornis minor and white rhinoceros Ceratotherium simum simum in Ndumu Game Reserve, South Africa. Biological Conservation, 47, 109-122.

Dinerstein, E. (2003) The Return of the Unicorns: The Natural History and Conservation of the Greater One-Horned Rhinoceros. Columbia Press, New York, USA.

Dinerstein, E. \& Price, L. (1991) Demography and habitat use by greater one-horned rhinoceros in Nepal. Journal of Wildlife Management, 55, 401-411.

DNPWC (Department of National Parks and Wildlife Conservation) (2000) Rhino Count 2000 Initial Report. DNPWC, Kathmandu, Nepal.

DNPWC (Department of National Parks and Wildlife Conservation) (2005) Annual Progress Report. DNPWC, Kathmandu, Nepal.

DNPWC (Department of National Parks and Wildlife Conservation) (2009) The Status and Distribution of the Greater One-Horned Rhino in Nepal. DNPWC, Kathmandu, Nepal.

DNPWC (Department of National Parks and Wildifife Conservation) (2011) Annual Progress Report. DNPWC, Kathmandu, Nepal.
Ferreira, S.M., Greaver, C.C. \& Knight, M.H. (2011)

Assessing the population performance of black rhinoceros in Kruger National Park. South African journal of Wildife Research, 2, 121-136.

Galli, N.S. \& Flamand, J.R.B. (1996) Darting and marking black rhinoceros on foot: part of monitoring and population estimation technique in Hluhluwe-Umfolozi Park, South Africa. Pachyderm, 21, 33-38.

Jhala, Y.V., Qureshi, Q., Gopal, R. \& Sinha, P.R. (eds) (2011) Status of Tigers, Co-Predators and Prey in India 2010. National Tiger Conservation Authority, Government of India New Delhi, and Wildlife Institute of India, Dehradun, India.

Jnawali, S.R. (1995) Population Ecology of Greater One-Horned Rhinoceros (Rhinoceros unicornis) with Particular Emphasis on Habitat Preference, Food Ecology and Ranging Behaviour of a Reintroduced Population in Royal Bardia National Park in Lowland Nepal. PhD thesis. Agricultural University of Norway, Ås, Norway.

Jnawali, S.R. \& Wegge, P. (1993) Space and habitat use by a small re-introduced population of greater one-horned rhinoceros (Rhinoceros unicornis) in Royal Bardia National Park in Nepal-a preliminary report. In Rhinoceros Biology and Conservation-Proceedings of an International Conference (ed. O.A. Ryder), pp. 208-217. Zoological Society, San Diego, USA.

Kiwia, H.D. (1989) Black rhinoceros Diceros bicornis (L): population size and structure in Ngorogoro crater, Tanzania. African Journal of Ecology, 27, 1-6.

LANG, E.M., Leutnegger, M. \& Tobler, K. (1977) Indian rhinoceros (Rhinoceros unicornis) births in captivity. International Zoo Yearbook, 17, 237-238.

LAURIE, W.A. (1978) The Ecology and Behaviour of the Greater One-Horned Rhinoceros. PhD thesis. University of Cambridge, Cambridge, UK.

LAURIE, W.A. (1982) Behavioural ecology of the greater onehorned rhinoceros (Rhinoceros unicornis). Journal of Zoology, 196, 307-341.

Murphy, S. T., Subedi, N., Jnawali, S. R., Lamichnane, B. R., Upadhyay, G. P., Kock, R. et al. (2013) Invasive mikania in Chitwan National Park, Nepal: the threat to the greater one-horned rhinoceros Rhinoceros unicornis and factors driving the invasion. Oryx, 47, 361-368.

Ngene, S., Bitok, E., Mukeka, J., Gakuya, F., Omondi, P., Kimitei, K. et al. (2011) Census and ear notching of black rhinoceros (Diceros bicornis michaeli) in Tsavo east National Park, Kenya. Pachyderm, 49, 61-69.

Otis, D.L., Burnham, K.P., White, G.C. \& Andersen, D.R. (1978) Statistical inference from capture data of closed population. Wildlife Monographs, 2, 2-13.

OWEn-SMith, R.N. (1988) Megaherbivores: The Influence of Very Large Body Size in Ecology. Cambridge University Press, Cambridge, UK.

Patton, F., Campbell, P. \& Parfet, E. (2007) Establishing a monitoring system for black rhinoceros in the Solio Game Reserve, central Kenya. Pachyderm, 43, 87-95.

Poudyal, M., Rothley, K. \& Knowler, D. (2009) Ecological and economic analysis of poaching of the greater one-horned rhinoceros (Rhinoceros unicornis) in Nepal. Ecological Applications, 19, 1693-1707.

Stanley, T.R. \& Burnham, K.P. (1999) A closure test for time-specific capture-recapture data. Environmental Ecological Statistics, 6, 197-209.

Stein, E.B., Erckie, B., Fuller, T.K. \& Marker, L. (2010) Camera trapping as a method for monitoring rhino populations within the Waterberg Plateau Park, Namibia. Pachyderm, 48, 67-70. 
Subedi, N. (2012) Effect of Mikania micrantha on the demography, habitat use and nutrition of greater one-horned rhinoceros in Chitwan National Park, Nepal. PhD thesis. Forest Research Institute University, Dehradun, India.

Sukumar, R. (1989) The Asian Elephant: Ecology and Management. Cambridge University Press, Cambridge, UK.

Talukdar, B.K. (2009) Asian rhino specialist group report. Pachyderm, 46, 14-17.

Thapa, K., Nepal, S., Thapa, G., Bhatta, S. R. \& Wikramanayake, E. (2013) Past present and future conservation of the greater one-horned rhinoceros Rhinoceros unicornis in Nepal. Oryx, 47, 345-351.

Walpole, M.J., Morgan-Davies, M., Milledge, S., Bett, P. \& Leader-Williams, N. (2001) Population dynamics and future conservation of a free ranging black rhinoceros (Diceros bicornis) population in Kenya. Biological Conservation, 99, 237-243.

White, G.C. \& Burnham, K.P. (1999) Program MARK: survival estimation from populations of marked animals. Bird Study, 46, 120-138.
Yonzon, P. (1994) Count Rhino 1994. Report Series No. 10. WWF Nepal Program, Kathmandu, Nepal.

\section{Biographical sketches}

Naresh Subedi's interests are the ecology of rhinoceroses, invasive species and the human-wildlife interface. SHAnt Raj JNAwALI is Director of the National Trust for Nature Conservation, and specializes in management of megaherbivores in human-dominated landscapes. MAHESWAR DHAKAL is interested in sustainable protected area management. NAREndRa PRADHAN was formerly the Chief Warden of Chitwan National Park; he studies the ecology of Asian elephants. BABU RAM LAMICHHANE is interested in applying geographical information systems and remote sensing to habitat dynamics. S A B IT A MALLA is interested in the human-wildlife interface. RAJAN AMIN specializes in the conservation of Asian and African grassland ecosystems. YADVENDRADEV JHALA is interested in conservation, ecology, and population monitoring of large carnivores. 